IJADR

International Journal of Alcohol and Drug Research

The Official Journal of the Kettil Bruun Society for Social and Epidemiological Research on Alcohol

doi: 10.7895/ijadr.v3i1.177

IJADR, 2014, 3(1), 121 - 125

ISSN: 1925-7066

\title{
Australia plays 'catch-up’ with Fetal Alcohol Spectrum Disorders
}

\section{Commentary}

\begin{abstract}
Australians are amongst the highest consumers of alcohol worldwide, and "risky" drinking is increasing in young women. Contrary to the advice in national guidelines, drinking in pregnancy is common. Many women don't understand the potential for harm to the unborn child and $20 \%$ have a "tolerant" attitude to drinking during pregnancy. As attitude, rather than knowledge, predicts risk of drinking in a future pregnancy, this presents a challenge for public health campaigns. Alcohol is teratogenic, crosses the placenta, and contributes to a range of physical, developmental, learning and behavioural problems, including fetal alcohol spectrum disorders (FASD). As nearly half of all pregnancies in Australia are unplanned, inadvertent exposure to alcohol is common. Good-quality prevalence data on FASD are lacking in Australia, although alcohol use at "risky" levels is well documented in some disadvantaged communities. In the last decade, clinicians, researchers, governments and nongovernmental organizations have shown renewed interest in addressing alcohol use in pregnancy and FASD. This has included a parliamentary inquiry into FASD, provision of targeted funding for FASD, and development of educational materials for health professionals and the general public. Key challenges for the future are to prevent FASD and to offer timely diagnosis and help to children and families living with FASD. The implementation of evidence-based interventions known to decrease access to, and excessive use of, alcohol in our society will aid in the prevention of FASD. The development of national diagnostic tools for screening and diagnosis, and the training of health professionals in the management of FASD, are urgently needed.
\end{abstract}

Keywords: Fetal alcohol syndrome; alcohol pregnancy

\section{Alcohol in Australia}

Australia has a problem with alcohol misuse! The WHO estimates that every Australian over the age of 15 years drinks 10 litres of pure alcohol per year (WHO, 2011). This equates to over two alcoholic drinks per person per day-no mean feat when you consider that many people do not drink, and that it is illegal to sell alcohol to anyone under the age of 18 years and (in some jurisdictions) to serve alcohol to minors without express parental permission.
When I was growing up in Australia in the 1960s, public bars were male-only domains; women and children rarely went to the pub. In association with the liberation of women in society and the feminisation of the workforce, the culture of drinking changed dramatically (Burns et al., 2012). Women are now welcome in all liquor outlets, many women regularly drink alcohol, and there is an epidemic of binge drinking in teens. Indeed, between 1995 and 2006 the rate of risky and high-risk drinking among women more than doubled, to $12 \%$ (Australian Bureau of Statistics, 2006).

\section{Alcohol and Pregnancy}

Although national guidelines recommend that women who are pregnant or planning a pregnancy should avoid alcohol (NHMRC, 2009), Australian data suggest that between $34 \%$ and $59 \%$ continue to drink alcohol during pregnancy (Colvin et al., 2007; O’Callaghan et al., 2007; Peadon et al., 2010). In one study, $20 \%$ of women reported binge drinking on at least one occasion in early pregnancy (O’Callaghan et al., 2007). Although drinking rates don't differ between Indigenous and non-Indigenous women, a binge drinking pattern is more often observed in Indigenous women. In a study in Perth, Western Australia, 23\% of Aboriginal women reported becoming intoxicated during pregnancy (Eades et al., 2008), and in a study in the very remote Fitzroy Valley in Western Australia over 50\% of women drank during their pregnancy (during 2001 to 2003), most at high-risk levels (Elliott et al., 2012; Fitzpatrick, J., personal communication, February 2014).

In New South Wales, alcohol-related hospital admissions during pregnancy are not uncommon and pregnancy and labor may be the first time alcohol misuse or dependency is identified (Burns et al., 2011). Poor obstetric and neonatal outcomes often result, highlighting the need for drug and alcohol services for pregnant women (Burns et al., 2011) and for routine screening for alcohol use, ideally using a validated instrument (Muggli et al., 2010). Regrettably, Australian health professionals are reluctant to ask and advise about alcohol use during pregnancy, in part due to their fear of upsetting, angering or stigmatizing women. Thus, many women who are drinking are not identified until well into pregnancy (Payne et al., 2005; Elliott et al., 2006). Interestingly, women have certain expectations of health professionals. Over $90 \%$ of Australian women say that they want to be asked about their alcohol use in 
pregnancy, to be warned about its potential harms, and to be advised not to drink in pregnancy (Peadon et al., 2011). We have shown that changes to health professionals' knowledge and practice can be achieved by provision of educational resources, and such resources must be made available nationally (Payne et al., 2011a; Payne et al., 2011b).

Australian women are often unaware of alcohol's potential harms to the fetus, but even when they do have that knowledge, some choose to drink in pregnancy. The women at greatest risk of drinking are those who regularly drink at risky levels, who smoke, whose partners drink, and who drank alcohol-perhaps with no obvious ill effects to the child-in a previous pregnancy. A tolerant attitude towards alcohol use in pregnancy is also an important predictor (Peadon et al., 2010; Peadon et al., 2011). Identification of women most at risk will inform prevention programs. If they are to influence drinking behavior, however, such programs must not only provide knowledge, but promote attitudinal and, hence, behavioral change-a much more difficult challenge (Peadon et al., 2010; Peadon et al., 2011). In the case of Indigenous Australians, an understanding of the historical trauma, continuing disadvantage and stresses that underpin alcohol use is crucial to addressing the problem (D’Antoine, H., personal communication). Prevention of alcohol use in pregnancy requires a multi-pronged attack, including addressing determinants of disadvantage such as poor and overcrowded housing, lack of education, poor access to health care and lack of opportunities for employment (Elliott and Bower, 2004).

\section{Alcohol and the Unborn Child}

The teratogenicity of alcohol has long been known, as has its potential to irreparably damage the vulnerable developing brain; however, no safe level of intake has been established. So, when women drink during pregnancy, there is always a risk of damage to the unborn child, causing Fetal Alcohol Spectrum Disorders (FASD). As up to $50 \%$ of pregnancies in Australia are unplanned (Colvin et al., 2007), there is also significant risk of inadvertent exposure at the critical early stages of embryology, highlighting the need for early education of girls.

The year 2013 marked 40 years since the description of Fetal Alcohol Syndrome (FAS) in the English-language literature (Jones et al., 1973), yet FASD remains a "hidden" cause of disability in many parts of the world, and Australia is no exception (Elliott and Bower, 2004; Parliament of Australia, 2012). Australia was slow to recognise FASD and is now playing catch-up. Prior to 2000, few cases were reported in the literature, and we still have no accurate data on FASD prevalence. Published data on the prevalence of FAS are likely underestimates, due to under-diagnosis and underreporting of cases and lack of a mechanism for recording diagnoses (Allen et al., 2007; Bower et al., 2000; Elliott et al. 2008; Harris et al., 2003). We await publication of Australia's first population-based study, conducted in a high-risk Aboriginal population in the remote Fitzroy Valley, which will provide prevalence data that will likely be applicable to similar communities throughout Australia (Elliott et al., 2012; Fitzpatrick et al., 2012; Fitzpatrick et al., 2013). For the future, we require a trained workforce and a standardized approach to screening, diagnosis, identification and registration of cases.

\section{Australia is catching up on FASD}

Much has been achieved in the field of FASD in Australia since 2000; the literature reflects the high level of productivity of a relatively small group of researchers and clinicians, whose efforts have been supported by governments and NGOs (Burns et al., 2012). Interest in FASD was initially led by researchers, but the establishment by the Ministerial Council on Drugs Strategy, in 2006, of an Intergovernmental Committee on Drugs Working Party for looking into FASD was a catalyst to increasing recognition of FASD across government departments of health, education, disability and justice. This multi-disciplinary working party identified significant gaps in services (Peadon et al., 2009) and treatment (Peadon et al., 2008) for FASD; convened the first national conference on FASD in 2008; and produced a monograph updating the status of FASD in Australia (Burns et al., 2012). In 2006, the Prime Minister's Science Engineering and Innovation Council (PMSEIC) convened a Working Group on Aboriginal and Torres Strait Islander (ATSI) Health with a focus on maternal, fetal and post-natal health. In their 2008 report they noted the alarming impact of alcohol on the fetus and the need for dedicated funding for research into the prevention of alcohol use in pregnancy and for prevalence studies in FASD, particularly in ATSI communities (PMSEIC, 2008). This recommendation finally came to fruition in 2014 with the award of three grants (with a total value of \$A2.8 million) for research in ATSI communities on three topics: increasing capacity for screening and diagnosis for FASD; a positive parenting program for families and communities living with FASD; and improving outcomes for people with FASD in the justice system (NHMRC, 2014). Government funding has recently been committed to the development of a screening and diagnostic tool for FASD, which would assist clinicians and standardize our approach in Australia (Watkins et al., 2012a; Watkins et al., 2012b).

Non-governmental organizations have supported researchers and communities alike. For example, the Foundation for Alcohol Research and Education (FAREhttp://www.fare.org.au/) has provided grants to establish a pilot FASD clinic in Sydney-Australia's first; examine the impact of FASD on families; investigate community understanding of the NHMRC guidelines; raise awareness of FASD through film; and evaluate the effect of a voluntary code of warning labels on beverages regarding the risks of drinking alcohol in pregnancy. FARE also led the development of a proposal for a national action plan for FASD, launched in September 2012 in Parliament House, Canberra (FARE, 2012), and jointly convened the first Australasian conference on FASD in 2013 with the Public Health Association of Australia. With government funding, FARE is currently developing an educational 
package for health professionals to help them ask and advise about alcohol use in pregnancy. The important advocacy and family support role of organizations such as No Fetal Alcohol Spectrum Disorders (NOFASD) Australia (http://www.nofasd.org.au/) cannot be underestimated.

In March 2011 a group of federal politicians established a bipartisan group, Parliamentarians for the Prevention of FASD, in recognition of the importance of FASD. Their advocacy led to the House of Representatives initiating an inquiry into the prevention and management of FASD in November 2011. The inquiry's report to the Federal Parliament in late 2012 identified FASD as a "hidden" disability (Parliament of Australia, 2012). It contained a number of recommendations, which received government approval. In response, in August 2013 the Commonwealth Government committed \$A20 million to an Australian Government Action Plan to reduce the impact of FASD between 2013-14 and 2016-17. The key priorities are prevention of FASD, with emphasis on Indigenous and other disadvantaged communities; improvement of services for women with alcohol dependency; better diagnosis and management of FASD; and a nationally coordinated, whole-government approach to research and workforce support. As of March 2014, implementation of this plan has not commenced.

\section{The Future}

Consistent with the International Charter on Prevention of FASD, recently published in Lancet Global Health (Jonsson et al., 2014), in future the emphasis in Australia must be on prevention. We must better disseminate recommendations from national guidelines that alcohol should be avoided by women who are pregnant or planning a pregnancy (NHMRC, 2009). We must implement prevention programs that are evidence-based, and we must raise community awareness about FASD. Governments must consider measures to limit access to alcohol in the general population, including taxation; minimum pricing; restrictions on the number and opening hours of liquor outlets; and limits on advertising and promotion of alcohol. These interventions have been proven to be effective in changing drinking behavior and would reduce drinking in pregnancy and, ultimately, FASD prevalence. Women with problem drinking should, ideally, be identified before they become pregnant and assisted to stop drinking in pregnancy. The new WHO Guidelines for the Identification and Management of Substance Use and Substance Use Disorders in Pregnancy (WHO, 2014), released in March 2014, will assist health professionals in advising and assisting patients. Other challenges include the need to identify and assist children living with FASD in order to help them become the best they can be, and to support their families-financially, emotionally, and in their parenting. In Australia, we urgently require training of health professionals to improve capacity for the diagnosis and management of FASD, funding for services, and a consistent approach to diagnosis. Above all, the approach to FASD must be co-ordinated, collaborative and national in scope.

\section{Acknowledgements}

Elizabeth Elliott is supported by a National Health and Medical Research Council of Australia (NHMRC) Practitioner Fellowships 2012-16 (No. 1021480).

\section{References}

Allen, K., Riley, M., Goldfeld, S., \& Halliday, J. (2007). Estimating the prevalence of fetal alcohol syndrome in Victoria using routinely collected administrative data. Australian and New Zealand Journal of Public Health, (31), 62-66.

Australian Bureau of Statistics (2006). Alcohol consumption in Australia: A snapshot, 2004-05. Report No. 4832.0.55.001. Canberra, Australian Bureau of Statistics. Retrieved from www.abs.gov.au/ausstats/abs@nsf/mf/4832.0.55.001

Burns, L., Black, E., Powers, J., Loxton, D., Elliott, E., Shakeshaft, A., \& Dunlop, A. (2011). Geographic and maternal characteristics associated with alcohol use in pregnancy. Alcoholism: Clinical and Experimental Research, 35, 1230-1237.

Bower, C., Silva, D., Henderson, T.R., Ryan, A., \& Rudy, E. (2000). Ascertainment of birth defects: The effect on completeness of adding a new source of data. Journal of Paediatrics and Child Health, 36, 574-576

Burns, L., Elliott, E., Black, E., \& Breen, C. (Eds.). (June 2012). Intergovernmental Committee on Drugs Working Party on Fetal Alcohol Spectrum Disorders. (Monograph.) Commonwealth Department of Health and Ageing. Retrieved from http://www.nationaldrugstrategy.gov.au/internet/drugs trategy/publishing.nsf/Content/55FEF3DF7E89405FC A257BB0007DF141/\$File/FASD-2012Monograph.pdf

Colvin, L., Payne, J., Parsons, D., Kurinczuk, J., \& Bower, C. (2007). Alcohol consumption during pregnancy in non-Indigenous West Australian women. Alcoholism: Clinical and Experimental Research, 32, 276-284.

Eades, S. (2004). Bibbulung Gnarneep (Solid Kid): A longitudinal study of a population-based cohort of urban Aboriginal children in WA. (Ph.D. thesis, unpublished.) University of Western Australia, Perth.

Elliott, E. J., \& Bower, C. (2004). FAS in Australia: Fact or fiction? Journal of Paediatrics and Child Health, 40, 8-10.

Elliott, E., Payne, J., Haan, E., \& Bower, C. (2006). Diagnosis of fetal alcohol syndrome and alcohol use in pregnancy: A survey of paediatricians' knowledge, attitudes and practice. Journal of Paediatrics and Child Health, 42, 698-703.

Elliott, E. J., Payne, J., Morris, A., Haan, E., \& Bower, C. (2008). Fetal alcohol syndrome: A prospective national surveillance study. Archives of Disease in Childhood, 93, 732-737.

Elliott, E., Latimer, J., Fitzpatrick, J., Oscar, J., \& Carter, M. (2012). There's hope in the valley. Journal of Paediatrics and Child Health, 48, 190-192. 
Fitzpatrick, J., Elliott, E., Latimer, J., Carter, M., Oscar, J., Ferreira, M., \& Hand, M. (2012). The Lililwan Project: Study protocol for a population based, active case ascertainment study of the prevalence of Fetal Alcohol Spectrum Disorders (FASD) in remote Australian Aboriginal communities. BMJ Open, 2, e000968. Retrieved from http://dx.doi.org/10.1136/ bmjopen-2012-000968

Fitzpatrick, J. P., Latimer, J., Ferreira, M., Martiniuk, A. L., Peadon, E., Carter, M., . . . Elliott, E. J. (2013). Development of a reliable questionnaire to assist in the diagnosis of fetal alcohol spectrum disorders (FASD). BMC Pediatrics, 13, 33.

Foundation for Alcohol Education and Research. (2011). The Australian Fetal Alcohol Spectrum Disorders Action Plan 2013-2016. Retrieved from http://www.fare.org.au/wp-content/uploads/2011/07/ FARE-FASD-Plan.pdf

Harris, K. R., \& Bucens, I. K. (2003). Prevalence of fetal alcohol syndrome in the Top End of the Northern Territory. Journal of Paediatrics and Child Health, 39, 528-533.

Jones, K. L., Smith, D. W., Ulleland, C. N., \& Streissguth, P. (1973). Pattern of malformation in offspring of chronic alcoholic mothers. Lancet, 301(7815), 12671271.

Jonsson, E., Salmon, A., \& Warren, K. (2014). The international charter on prevention of fetal alcohol spectrum disorder. The Lancet Global Health, 2, e135-e137. doi:10.1016/S2214-109X(13)70173-6.

Muggli, E., Cook, B., O’Leary, C., Forster, D., \& Halliday, J. (2010). Alcohol in Pregnancy: What questions should we be asking? Report to the Commonwealth Department of Health and Ageing. Murdoch Children's Research Institute. Retrieved from: http://www.alcohol.gov.au/internet/alcohol/publishing. nsf/Content/alc-preg-qu-doc

National Health and Medical Research Council of Australia. (2009). Australian Guidelines to Reduce Health Risks from Drinking Alcohol. Canberra, Australia: Commonwealth of Australia.

National Health and Medical Research Council of Australia. (2014). Fetal Alcohol Spectrum Disorder: Targeted call for research outcomes. Retrieved from http://www.nhmrc.gov.au/grants/outcomes-fundingrounds/fetal-alcohol-spectrum-disorder

O'Callaghan, F. V., O'Callaghan, M., Najman, J. M., Williams, G. M., \& Bor, W. (2007). Prenatal alcohol exposure and attention, learning and intellectual ability at 14 years: A prospective longitudinal study. Early Human Development, 83, 115-123.

Parliament of Australia, House of Representatives Standing Committee on Social Policy and Legal Affairs. (2012). FASD: The Hidden Harm. Inquiry into the prevention, diagnosis and management of Fetal Alcohol Spectrum Disorders. Canberra, Australia: Commonwealth of Australia.

Payne, J., Elliott, E., D’Antoine, H., O’Leary, C., Mahony, A., Haan, E., \& Bower, C. (2005). Health professionals' knowledge, practice and opinions about fetal alcohol syndrome and alcohol consumption in pregnancy. Australian and New Zealand Journal of Public Health, 29, 558-564.

Payne, J., France, K., Henley, N., D'Antoine, H., Bartu, A., O'Leary, C., . . . Bower, C. (2011a). Changes in health professionals' knowledge, attitudes and practice following provision of educational resources about prevention of prenatal alcohol exposure and fetal alcohol spectrum disorder. Paediatric and Perinatal Epidemiology, 25, 316-327.

Payne, J. M., France, K. E., Henley, N., D'Antoine, H. A., Bartu, A. E., Mutch, R. C., . . . Bower, C. (2011b). Paediatricians' knowledge, attitudes and practice following provision of educational resources about prevention of prenatal alcohol exposure and Fetal Alcohol Spectrum Disorder. Journal of Paediatrics and Child Health, 47, 704-710.

Peadon, E., Payne, J., Henley, N., D'Antoine, H., Bartu, A., O'Leary, C., . . . Elliott, E. (2010). Women's knowledge and attitudes regarding alcohol consumption in pregnancy: A national survey. $B M C$ Public Health, 10, 510. doi:10.1186/1471-2458-10510

Peadon, E., Payne, J., Henley, N., D'Antoine, H., Bartu, A., O'Leary, C., . . . Elliott, E.J. (2011). Attitudes and behaviour predict women's intention to drink alcohol during pregnancy: The challenge for health professionals. BMC Public Health, 11, 584.

Peadon, E., Rhys-Jones, B., Bower, C., \& Elliott, E. (2009). Systematic review of interventions for children with FASD. BMC Pediatrics, 9, 35. http://dx.doi.org/10.1186/1471-2431-9-35

Peadon, E., Fremantle, E., Bower, C., \& Elliott, EJ. (2008). International survey of diagnostic services for children with FASD. BMC Pediatrics, 8, 12. http://dx.doi.org/10.1186/1471-2431-8-12

Prime Minister's Science Engineering and Innovation Council (PMSEIC). (2008). Aboriginal and Torres Strait Island Health: The health of the adult begins in the womb. (A report of the PMSEIC Working Group). Canberra, Australia: Australian Government Department of Industry. Retrieved from http://www.innovation.gov.au/science/PMSEIC/Docu ments/AboriginalandTorresStraitIslandHealth.pdf

Watkins R. E., Elliott, E. J., Wilkins, A., Mutch, R. C., Fitzpatrick, J. P., Payne, J. M., . . . Bower, C. (2012a). Consensus diagnostic criteria for fetal alcohol spectrum disorders in Australia: A modified Delphi study. BMJ Open, 25, 2.

Watkins R. E., Elliott, E. J., Wilkins, A., Mutch, R. C., Fitzpatrick, J. P., Payne, J. M., . . Bower, C. (2012b). Health professionals' perceptions about the adoption of existing guidelines for the diagnosis of fetal alcohol spectrum disorders in Australia. BMC Pediatrics, 12, 69.

World Health Organization. (2011). Alcohol consumption by country. Global status report on alcohol and health. Geneva, Switzerland: Author.

World Health Organization. (2014). Guidelines for the identification and management of substance use and substance use disorders in pregnancy. Geneva: Author. 
Elizabeth Jane Elliott, A.M., M.D., M.Phil., MBBS, FRACP, FRCPCH, FRCP

Professor of Paediatrics and Child Health, University of Sydney; Consultant Paediatrician, The Sydney Children's Hospitals Network; and Practitioner Fellow, National Health and Medical Research Council of Australia

(Westmead), Locked Bag 4001

Westmead, 2145, NSW, Australia

Telephone: 61298453448

Fax: 61298453389

E-mail: Elizabeth.elliott@health.nsw.gov.au 